\title{
Intervention to improve screening and treatment of sepsis
}

\author{
Morten Z Plambech ${ }^{1 *}$, Helle L Ipsen² \\ From Danish Society for Emergency Medicine: Research Symposium 2010 \\ Roskilde, Denmark. 20-21 May 2010
}

\section{Background}

Audits have elucidated that sepsis is a frequent cause of death in the hospitals of Region of Zealand. International studies have shown that the survival of sepsis can be increased by introducing a "standard-package" containing 6 elements, for screening and treatment. Therefore, it was decided that all departments in the region have to implement a regional guideline for sepsis. Acute Division in Nykøbing F. has studied whether a systematic way to implement this guideline, will increase the number of patients, who receive a proper screening and treatment.

\section{Methods}

Intervention Study, using the Breakthrough Series method. The target group for intervention was all patients with suspected infection and with two or more SIRS criteria, who were compared with historical controls. Interventions: Education of the staff (78\%) working in Acute Division, knowledge-support tools such as pocket cards, checklists, posters and IT access to the guideline, and increased focus on measuring and documenting of vital parameters.

Baseline patients $(\mathrm{N}=26)$ were patients in a random week, who had the same criteria as the target group. The effect of the interventions were measured after 18 weeks by an audit survey of target groups of patients $(\mathrm{N}=35)$.

Implementation rate was continuously monitored with SPC.

\section{Results}

Of the staff, $78 \%$ received formal education.

At baseline, 8\% off the target group received the full screening and treatment. All patients had measured vital signs, 38\% off the patients received 3-6 elements off the full "package".

After the intervention, follow-up showed that $3 \%$ of the patients received all elements in screening and treatment of sepsis, and an increasing amounts of patients $(54,3 \%)$ received 3-6 elements of the full "package". The SPC showed that follow-up on vital signs and delay in treatment with antibiotic, was the problem according to the full "package".

\section{Conclusion}

The project demonstrated that a systematic process with several simultaneous actions has an increase in the awareness of sepsis although not to full extent. In addition, screening and treatment of sepsis were improved. A subsequent follow-up will show whether mortality (HSMR) has declined with the introduction of the regional guideline on sepsis.

\section{Author details \\ ${ }^{1}$ Anæstesiafdeling. Nykøbing F. Sygehus. Region Sjælland, Denmark. ${ }^{2}$ AMA, Akutafdelingen. Nykøbing F. Sygehus. Region Sjælland, Denmark.}

Published: 17 September 2010

doi:10.1186/1757-7241-18-S1-P17

Cite this article as: Plambech and Ipsen: Intervention to improve screening and treatment of sepsis. Scandinavian Journal of Trauma, Resuscitation and Emergency Medicine 2010 18(Suppl 1):P17.

* Correspondence: mzp@regionsjaelland.dk

${ }^{1}$ Anæstesiafdeling. Nykøbing F. Sygehus. Region Sjælland, Denmark

Full list of author information is available at the end of the article 